\title{
DESIGN OF SOL-GEL COPPER OXIDE BASED COATING FOR SOLAR ENERGY APPLICATIONS
}

\author{
Amany Khaled ${ }^{1,2}$, Nahed El-Mahallawy ${ }^{2}$, Madiha Shoeib ${ }^{3}$ and Mostafa R.A. Atia ${ }^{1}$ \\ ${ }^{1}$ Dept. of Mechanical Engineering, Arab Academy for science technology and maritime transport, Cairo, Egypt \\ 2: Dept. of Production and Mechanical Design, Ain Shams University, Cairo, Egypt \\ 3: Central Metallurgical Research Center, Cairo, Egypt
}

\begin{abstract}
:
Solar energy harvesting is of a great interest lately as it's a clean and environmentally friendly energy source. Therefore, Solar selective coatings development became one of the pioneering research routes nowadays. Copper oxide based films were prepared by a sol-gel route and deposited on a stainless steel substrate via dip coating. The solution was prepared with several concentrations of polyethylene glycol as a surfactant and agglomeration controlling agent. The effect of several concentrations on the optical properties was studied. The microstructure of the coats was discussed in details reflecting on the optical properties as well. In general, the copper oxide based coats have shown uniform and dark visual appearance with acceptable adherence. The coats have been successfully prepared and analysed with a promising absorptivity up to $96.3 \%$ with an optical band gap that varies between $2.5 \mathrm{eV}$ and $3.03 \mathrm{eV}$.
\end{abstract}

Keywords: Solar selective coating, copper oxide, PEG, sol-gel, bandgap, characterization.

\section{INTRODUTION}

Among all transition metal oxides, copper oxide $(\mathrm{CuO})$ has gained a great interest in the solar energy harvesting field due to its unique dielectric and optical properties [1]. $\mathrm{CuO}$ is widely known as a promising solar selective material with a low cost preparation procedure. $\mathrm{Cu}_{2} \mathrm{O}$, another oxide of copper, shows good solar absorption but lower than that of $\mathrm{CuO}$ [2]. $\mathrm{CuO}$ has a band gap reported between 1.3 and $1.7 \mathrm{eV}$ with a black color and partial transparency in the visible range [3].

Several copper oxide preparation techniques are available and have shown reliable results in thin film formation. However, due to the cost-viability of the sol-gel technique as one of the easiest ways to produce metal oxide layers over different substrates, it has gained a wide range of research interest through the past couple of years. As stated clearly in [4], sol-gel preparation can be controlled through adjusting several parameters as the precursor's concentration, the solvent's type, the solution's $\mathrm{pH}$ value, types of additives, heat treatment, solution aging, ... etc. Moreover, the particles formed in gel matrix possess uniform shape and size that enhances the optical, electrical, magnetic and other intrinsic nature of the materials.

Copper oxide was successfully prepared in several previous literatures with different applications and requirements. Halin et. al [5] used sol-gel method to prepare cuprous oxide thin films to coat solar cells. They have proven that adding a polymeric additive to the solution steps like polyethylene glycol (PEG) can enhance the properties of thin films relatively. Hashim et. al [6] discussed the effect of molarity concentration on the properties of the synthesized films. They 
found that the transmittances of $\mathrm{CuO}$ thin films decrease as the thickness increase with increase of molar concentrations. They have also deduced that electrical properties show current increase when the molar concentration increases. Mallick et. al [7] studied the effect of changing the solvent through the sol-gel preparation on the microstructure, properties and behavior of thin films. They compared ethanol and propanol and their effect on optical absorption. Bibi et. al [8] discussed the results of changing the annealing temperature over the different properties of films. They observed that a structural change in the prepared copper oxide was observed from cluster formation to Nano-fibrils by increasing the annealing temperature.

In the present work, a route for preparing solar selective coat based on copper oxide using sol-gel technique is used. The authors studied the effect of the variation of the weight percentage of the addition of a polymer, mainly PEG, on the optical properties of the targeted coat.

\section{MATERIALS AND METHODS}

Different applications monitor the sol-gel synthesis route by using a certain precursor, adding a certain agent, using a specific solvent or using a unique substrate. The three basic precursors used previously in copper oxide film preparation were copper nitrate, copper acetate and copper chloride. As stated in [9], these three metal salts can give successful gelled structure and consequently, produce promising thin films.

In this study, the percentage of added PEG is increased and studied in an attempt to increase the optical properties of the coat. This can be done by increasing the heat treatment temperature up to $600 \mathrm{oC}$. The polymeric chains in that case, start to break down leaving a porous structured film behind in addition to some carbon content that can both contribute to the increase in absorption of solar energy.

\section{EXPERIMENTAL WORK}

As previously mentioned, the preparation of metal oxide from an acetate precursor is the widely used procedure. Consequently, the procedure of sol-gel preparation was based on that mentioned in other literature [3], [6], [15], [18] with some modifications based on the target of this experimental work. Chemicals used with their predefined masses are shown in details in Table 2 . In [6], it was stated that a molar concentration of $0.5 \mathrm{M}$ gave the best stable results. Therefore, it was used as a reference molar concentration for the rest of procedure. The detailed steps of solgel preparation of copper oxide thin film were as follows:

\section{To prepare $25 \mathrm{ml}$ of the solution:}

1- Add the PEG to $5 \mathrm{~mL}$ of distilled water and leave it under stirring for 5 minutes.

2- Add the previous solution dropwise to the IPA in addition to the DEA and leave stirring for 1 hour.

3- Add the $\mathrm{CuAc}$ to the resultant solution and leave it stirring overnight for $50 \%$ evaporation of the total volume.

4- By the next day, $25 \mathrm{ml}$ of the solution are left.

Leave the solution in a sealed beaker without stirring for stabilization one whole day before dip coating. 
Table 1 shows a cross mapping between different previous literature and the type of substrate, precursor and solvent used. It can be observed that the most frequently used precursor was copper acetate and the commonly used solvent was isopropanol.

In this study, the percentage of added PEG is increased and studied in an attempt to increase the optical properties of the coat. This can be done by increasing the heat treatment temperature up to $600^{\circ} \mathrm{C}$. The polymeric chains in that case, start to break down leaving a porous structured film behind in addition to some carbon content that can both contribute to the increase in absorption of solar energy.

\section{EXPERIMENTAL WORK}

As previously mentioned, the preparation of metal oxide from an acetate precursor is the widely used procedure. Consequently, the procedure of sol-gel preparation was based on that mentioned in other literature [3], [6], [15], [18] with some modifications based on the target of this experimental work. Chemicals used with their predefined masses are shown in details in Table 2 . In [6], it was stated that a molar concentration of $0.5 \mathrm{M}$ gave the best stable results. Therefore, it was used as a reference molar concentration for the rest of procedure. The detailed steps of solgel preparation of copper oxide thin film were as follows:

\section{To prepare $25 \mathrm{ml}$ of the solution:}

5- Add the PEG to $5 \mathrm{~mL}$ of distilled water and leave it under stirring for 5 minutes.

6- Add the previous solution dropwise to the IPA in addition to the DEA and leave stirring for 1 hour.

7- Add the $\mathrm{CuAc}$ to the resultant solution and leave it stirring overnight for $50 \%$ evaporation of the total volume.

8- By the next day, $25 \mathrm{ml}$ of the solution are left.

Leave the solution in a sealed beaker without stirring for stabilization one whole day before dip coating. 
DESIGN OF SOL-GEL COPPER OXIDE BASED COATING FOR SOLAR ENERGY APPLICATIONS

Table 1 - Cross mapping between previous literature and the used precursors, substrates and solvents

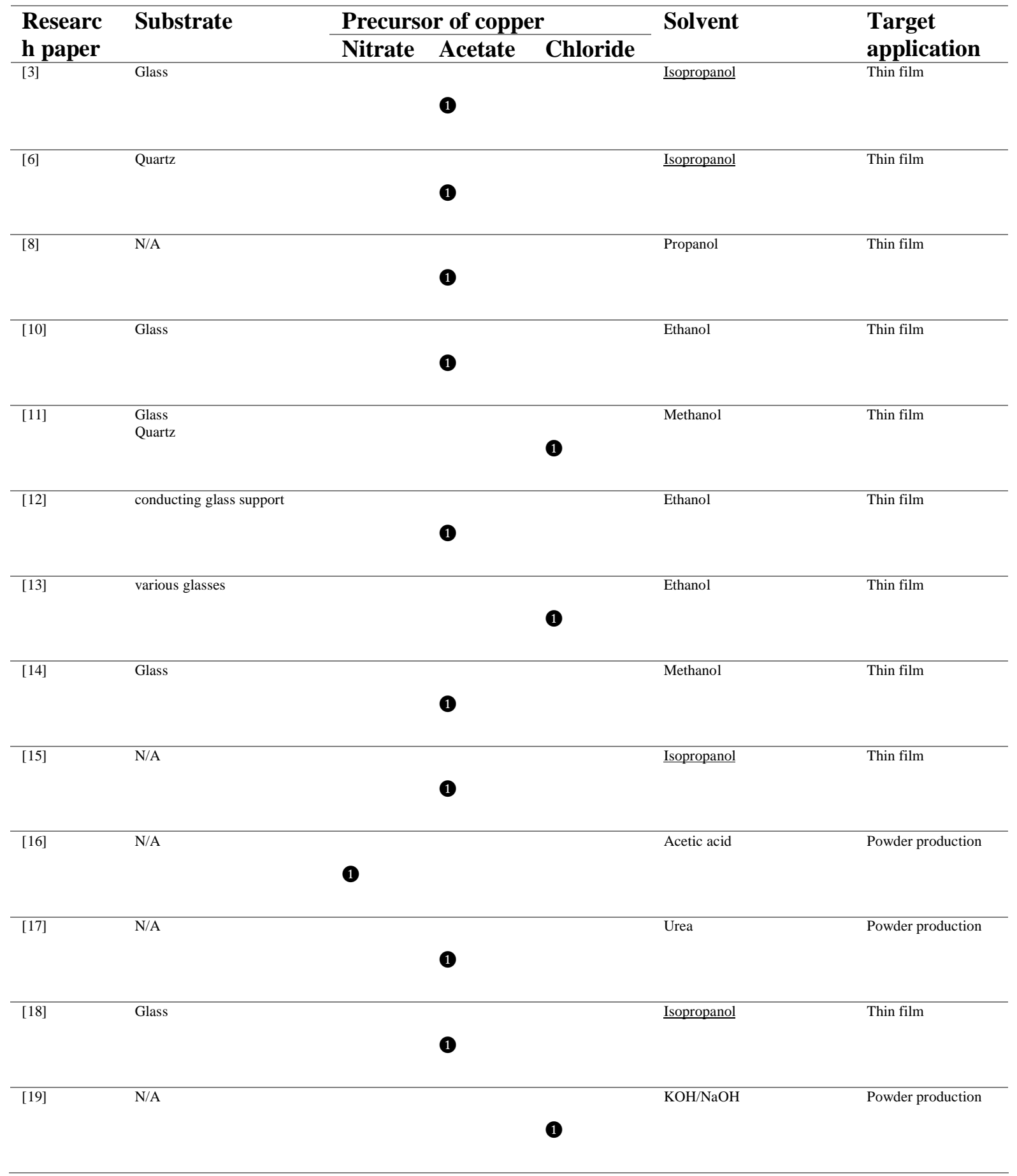


DESIGN OF SOL-GEL COPPER OXIDE BASED COATING FOR SOLAR ENERGY APPLICATIONS

Table 2 - Chemicals used in sol-gel preparation of $25 \mathrm{ml}$ of the solution

\begin{tabular}{llll}
\hline Chemical & Formula & $\begin{array}{l}\text { Mass or Volume } \\
\text { used in preparation }\end{array}$ & $\begin{array}{l}\text { Abbreviati } \\
\text { on in } \\
\text { literature }\end{array}$ \\
\hline $\begin{array}{l}\text { Copper II acetate } \\
\text { monohydrate }\end{array}$ & $\mathrm{C}_{4} \mathrm{H}_{8} \mathrm{CuO}_{5}$ & $4.99[\mathrm{gm}]$ & $\mathrm{CuAc}$ \\
\hline Isopropyl alcohol & $\mathrm{C}_{3} \mathrm{H}_{8} \mathrm{O}$ & $45[\mathrm{~mL}]$ & IPA \\
\hline $\begin{array}{l}\text { Polyethylene glycol } \\
\text { [MW=4000] }\end{array}$ & $\mathrm{C}_{2 \mathrm{n}} \mathrm{H}_{4 \mathrm{n}+2} \mathrm{O}_{\mathrm{n}+1}$ & $3.15[\mathrm{gm}]$ & $\mathrm{PEG}$ \\
\hline Di-ethanol amine & $\mathrm{C}_{4} \mathrm{H}_{11} \mathrm{NO}_{2}$ & $2.5[\mathrm{~mL}]$ & DEA \\
\hline
\end{tabular}

The effect of PEG was investigated by increasing the wt\% of PEG with respect to the solvent. wt $\%$ of PEG with respect to the solvent was varied to be 5,10,15 and $20 \mathrm{wt} \%$ respectively. The resulting solution was homogeneous, viscous and deep dark blue in color without any suspensions or precipitates in all cases.

The substrate used in this research was Stainless Steel 304 (SS) cut at a size of $3 \mathrm{~cm} \mathrm{X} 10 \mathrm{~cm}$ with $1 \mathrm{~mm}$ thickness. To prepare the substrate samples for coating, all samples were sandblast and then cleaned by distilled water. Further cleaning and degreasing was achieved by having them immersed in acetone and submitted in an ultrasonic cleaner for 10 minutes. Samples were then carefully dehydrated by a flow of hot air and then dipped into the sol-gel with a withdrawal speed of $1 \mathrm{~cm} / \mathrm{min}$. Coat drying was carried out at $250^{\circ} \mathrm{C}$ for 15 minutes before heat treatment. According to [18] and [3], Sintering temperature must exceed $350^{\circ} \mathrm{C}$ in order to oxidize $\mathrm{Cu}$ into stable $\mathrm{CuO}$. In addition, in order to obtain a porous film structure to harvest more solar energy, PEG needed to be heated up to $550^{\circ} \mathrm{C}$ to vaporize. Thus, heat treatment temperature was chosen to be $600 \mathrm{oC}$ for 1 hour. The results section will discuss the effect of PEG wt\% variation on the optical properties in details.

Different measurements and characterization procedures were held in order to characterize the coating and test its functionality. The experimentally measured absorptivity and emissivity were measured using a UV spectrophotometer PG Instruments 90+ with integrating sphere and the infrared (IR) spectrometer Nicolet 380 FTIR respectively. Surface morphology and existing phases and compounds were investigated through SEM Camscan 44 and Philips PW 2404 XRAY Spectrometer respectively.

\section{RESULTS AND DISCUSSION}

Table 3 shows the nomenclature that will be used throughout this section corresponding to each sample referring to its properties with respect to the variation of PEG wt\%.

Table 3 - Nomenclature of prepared samples with properties variation

\begin{tabular}{cc}
\hline Sample Name & PEG wt\% \\
\hline P5 & $5 \%$ \\
\hline P10 & $10 \%$ \\
\hline P15 & $15 \%$ \\
\hline P20 & $20 \%$
\end{tabular}

4.1 UV-Visible absorptivity analysis:

For successful solar energy harvesting, absorption in the UV range is desirable to be maximized. Reflectance spectra in Uv-Vis range was collected through the wavelength range between 300- 
$700 \mathrm{~nm}$. Absorption was calculated based on the fact that $\mathrm{A}+\mathrm{R}+\mathrm{T}=1$, and since stainless steel is opaque, $\mathrm{T}=0$. Therefore, it can be assumed that $\mathrm{A}+\mathrm{R}=1$ and average absorptivity can be calculated through the integration involving the spectral solar irradiance according to [20] as follows

Where

$$
\alpha=\frac{\int_{0.3}^{0.7} I_{\text {sol }}(\lambda)(1-R(\lambda)) d(\lambda)}{\int_{0.3}^{0.7} I_{\operatorname{sol}(\lambda) d(\lambda)}}
$$

$\alpha \quad$ Average absorptivity

$I_{\text {sol }} \quad$ Solar irradiance

$\lambda \quad$ Wavelength

$R \quad$ Measured reflectance

The wt $\%$ of the PEG was increased gradually with respect to the solvent and its effect on the optical properties was determined.

Figure 1 shows the absorptivity trends of different PEG wt\%. Increasing the percentage of the PEG from $5 \%$ to $20 \%$ increased the absorptivity as a trend and as an average value as shown in Figure 3.

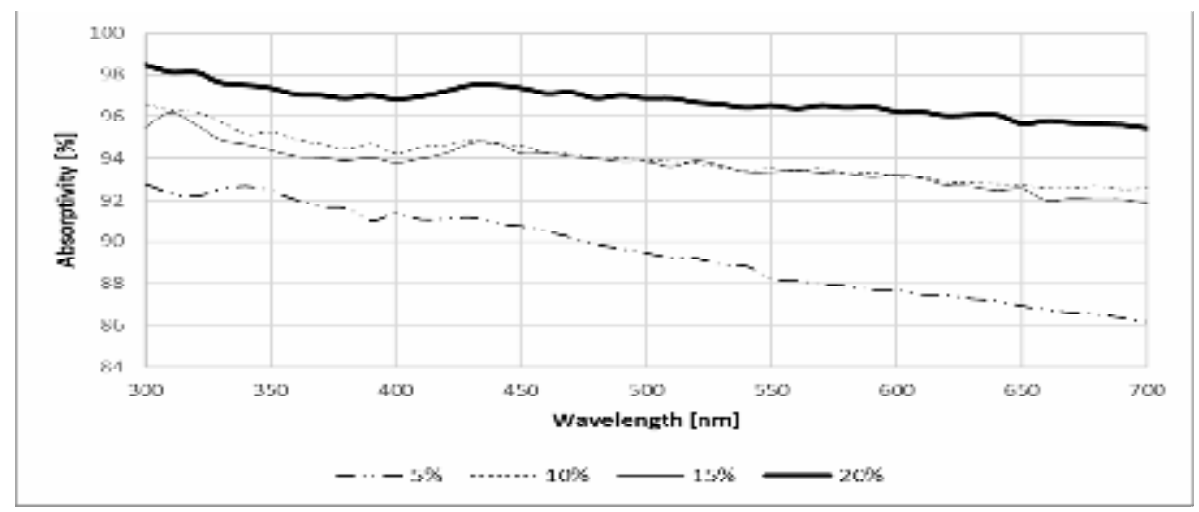

Figure 1 - Absorptivity spectra of CuO films with different PEG wt\%

The optical absorptivity can also contribute to the determination of the optical bandgap of the coat. As explained in [21] , a small bandgap allows a large range of photon absorption. However, in most cases, most of the photon energy is lost as heat. A large bandgap coat has low absorbance compared to others. Tauc plot was drawn for all samples as stated in [10] based on the following relation

$$
\alpha h v=A\left(h v-E_{g}\right)^{n}
$$

Where

$\alpha \quad$ Measured Absorptivity

hv Energy $[\mathrm{eV}]$

A Constant

$\mathrm{E}_{\mathrm{g}} \quad$ Bandgap [eV]

$n$ depends on the nature of the transition

, all reported similar bandgap values to [5], [7], [8], [10], [17], [22]previous literature ,such as reported that a better solar energy harnessing is [8]those obtained in this study. Maryam Bibi in 
, it [23]improved by widening the bandgap of copper oxide structures in particular. Moreover, in [22]was reported that porous structures always behold wide bandgaps. N. Zayyoun et. al in against $h w s i m p l y$ stated that obtaining the bandgap value corresponds to plotting the energy where their intersection obtains the value for the corresponding bandgap. $(\alpha h v)^{2}$ Figure 2 shows a sample of the tauc plots used to obtain the bandgap for several samples. This tauc plot corresponds to the sample P20 with the highest PEG content. Figure 3 shows the mapping between average absorptivity and calculated average bandgap of each sample type. It can be observed that there's a remarkable increase in the average bandgap with the increase of the PEG \%. This verifies the increase in porosity with the increase of the PEG \%. Increased absorptivity, however, can be explained by the existence of carbonic residuals from the PEG that were able to absorb more energy.

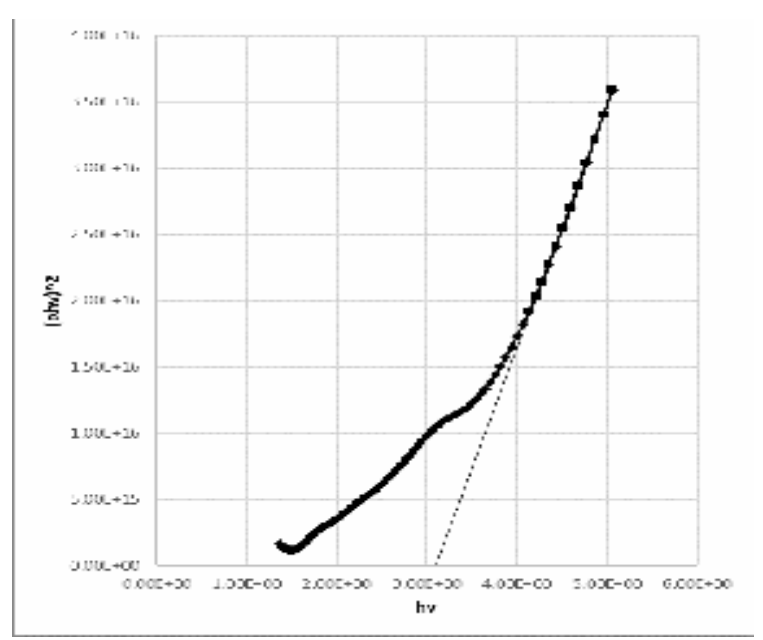

Figure 2 Sample Tauc plot corresponding to P20

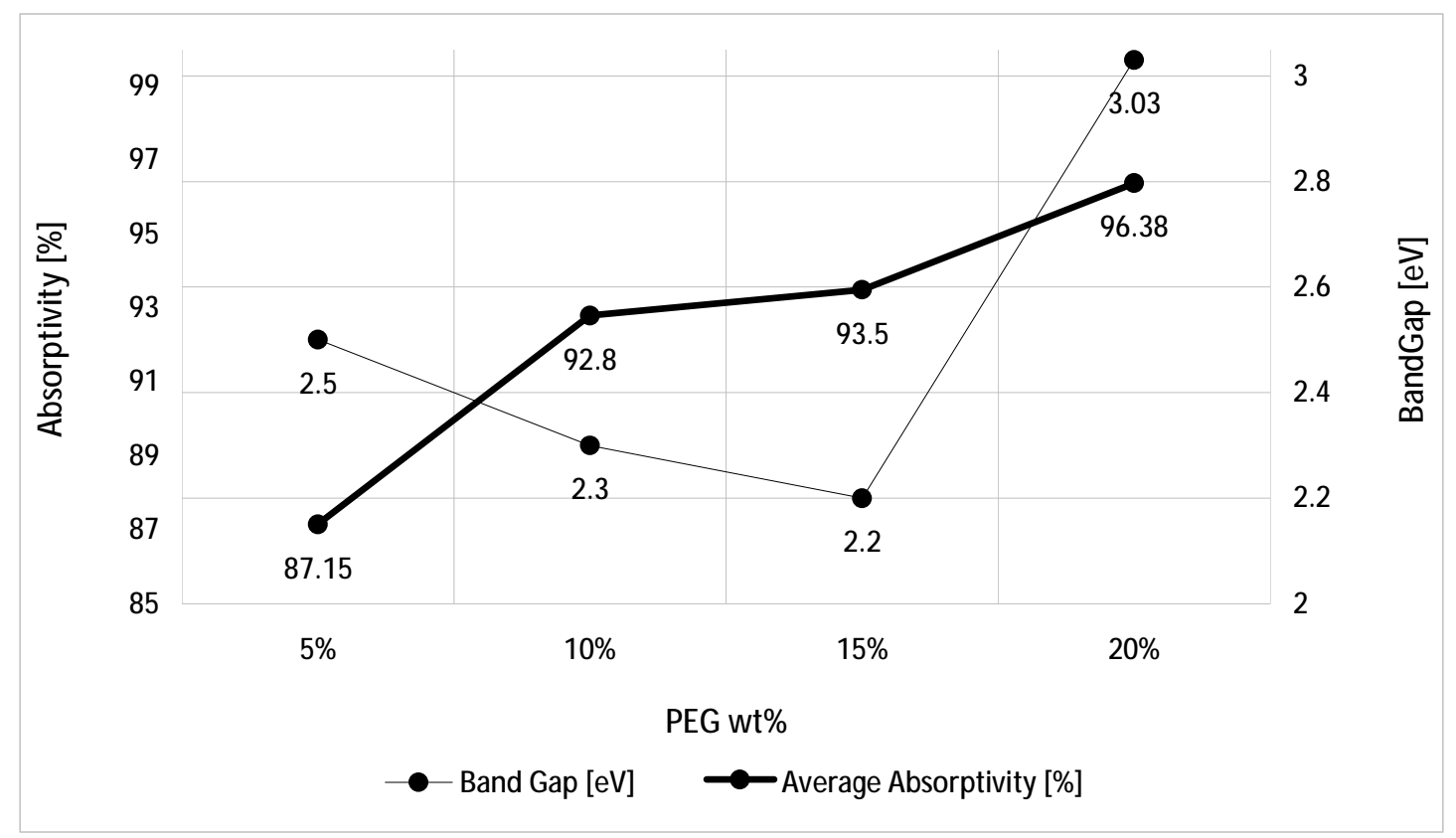

Figure 3-PEG wt\% Vs the Absorptivity and Band gap 


\subsection{IR emissivity measurement:}

In order to obtain a coat that has effective absorption in both the UV and the IR wavelength range, thermal emittance of the coat in the IR range should be minimized. To measure the thermal emittance, the following equation [20] was used from the data collected from the FTIR analysis represented in $R(\lambda)$ such that

Where

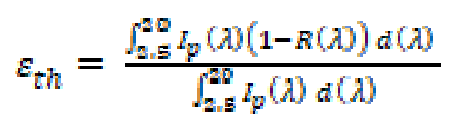

\section{$\varepsilon_{t h} \quad$ Thermal emittance [\%]}

$I_{p}(\lambda)$ Plank's blackbody at $100^{\circ} \mathrm{C}$

$R(\lambda)$ Reflectance value [\%]

It was observed that all coats have similar emissivity behavior as the sample shown in Figure 4. It was observed that the emissivity measurements of the copper oxide coats was very high with respect to other coats mentioned in previous literature that are used for solar energy capture .

shows the detailed values of each sample type. All coats with the variation of PEG wt\% were observed to have an emissivity that exceeds the $50 \%$ which is regarded as a very high emissivity in solar selective coating applications. This initiates the need of either a multi-layered structure coat or a mixture based coat that can reduce the emissivity of the copper oxide layer. This can be achieved by adding a thin reflective layer underneath the copper oxide layer and adding an antireflecting layer over it in order to entrap the collected solar radiations in between.

TABLE 4 detailed values of each sample type. All coats with the variation of PEG wt\% were observed to have an emissivity that exceeds the $50 \%$ which is regarded as a very high emissivity in solar selective coating applications. This initiates the need of either a multi-layered structure coat or a mixture based coat that can reduce the emissivity of the copper oxide layer. This can be achieved by adding a thin reflective layer underneath the copper oxide layer and adding an antireflecting layer over it in order to entrap the collected solar radiations in between.

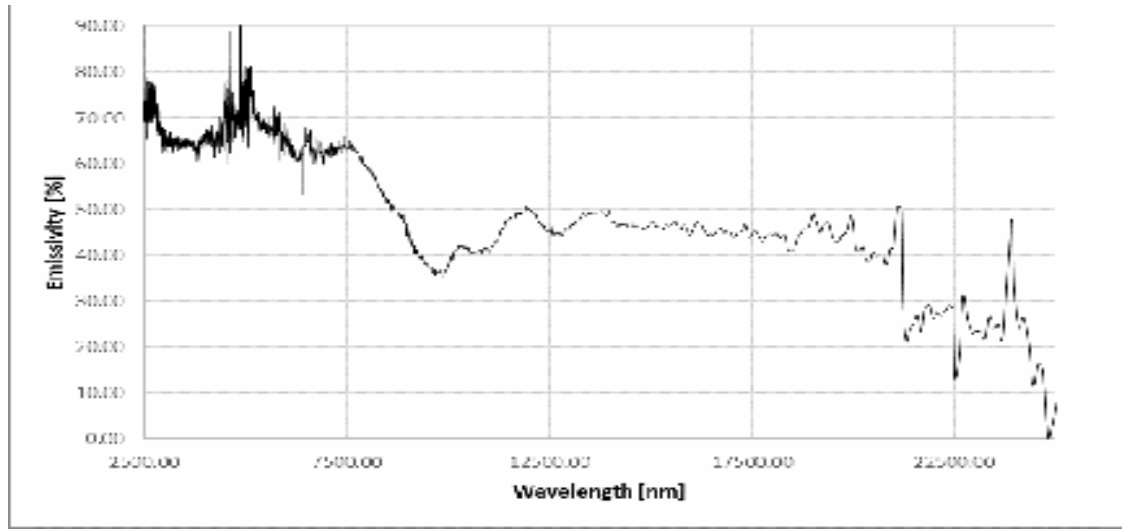

4.3 Selectivity of Coat Analysis:

Figure 4 - Sample FTIR spectra of coats of sample P20

The selectivity of a solar coat is measured by the ratio $\alpha / s_{\text {. }}$. However, this measurement can be misleading when the absorptivity is low and emissivity is relatively very low. Therefore, some other research, like [20], has adopted another definition of selectivity to be equal to $\alpha-\frac{1}{2} \varepsilon_{t h}$. They have stated that this formula defines an acceptable weight factor to emisšivity other than the ratioused. Compares the selectivity of samples using both stated formulas. 
Table 4 - Optical properties of different coats and selectivity measurements in the two proposed formulae

\begin{tabular}{ccccc}
\hline Sample & $\boldsymbol{\alpha}$ & $\boldsymbol{\varepsilon}$ & $\alpha / \varepsilon_{\text {th }} \mathbf{S}=$ & $\alpha-\frac{1}{2} \varepsilon_{t h} \mathbf{S}^{\prime}=$ \\
\hline P5 & 87.15 & 59.4 & 1.46 & 57.45 \\
\hline P10 & 92.8 & 64.3 & 1.44 & 60.66 \\
\hline P15 & 93.5 & 69.4 & 1.34 & 58.83 \\
\hline P20 & 96.38 & 68.9 & 1.39 & 61.93
\end{tabular}

Based on the selectivity measure of S, p20 is not the best candidate in selectivity though it has highest value of $\alpha$ and $\varepsilon$ which has a similar value to others. On the contrary, $\mathrm{S}$ ' has awarded the same sample, p20, the highest value of selectivity which contributes to the enhanced absorptivity.

\subsection{Surface Morphology Through Scanning Electron Microscopy(SEM):}

The morphology of the coat was analyzed using SEM images and compared to agreement with EDX stated in the upcoming sections. Table 5 shows the samples that were investigated through SEM analysis. Film thickness was measured through optical microscopic cross section investigation. It can be observed that a higher PEG content gave a more thick layer which is agreed with the emphasis previously introduced in [5].

Table 5- Characteristics of samples for SEM

\begin{tabular}{ccccc}
\hline Sample & PEG\% & $\boldsymbol{\alpha}[\%]$ & $\boldsymbol{\varepsilon}[\%]$ & Thickness [um] \\
\hline P5 & $5 \%$ & $86.3 \%$ & $59.5 \%$ & 2.96 \\
\hline P20 & $20 \%$ & $95 \%$ & $69.4 \%$ & 6.77 \\
\hline
\end{tabular}

Investigating the sample P5, sol-gel was prepared with the same procedure mentioned in the experimental section. By visual inspection, the resulting coat was homogeneous, adherent and uniform. Further investigation through the SEM images is shown in

Figure 5. Surface morphology is consistent with uniformly distributed closely packed islands of well-defined particles. With the 4000X magnification, semi-spherical grains of $\mathrm{CuO}$ can be well defined. Similar morphologies were reported in previous research such as in [24] where $\mathrm{CuO}$ particles were prepared via chemical precipitation method using Copper (II) chloride dehydrate as a precursor and annealed at $600^{\circ} \mathrm{C}$.

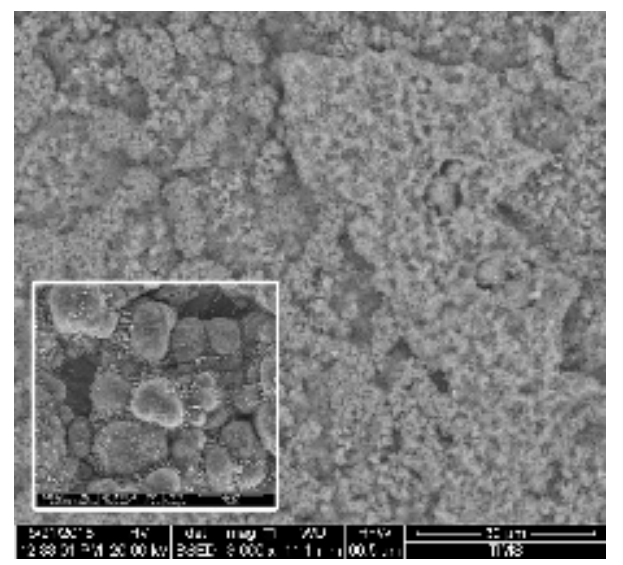

Figure 5 - SEM image at 3000X for sample P5 
Sample P20 corresponds to a PEG wt $\%=20 \%$ of the total solvent weight percentage. According to [25], a porous structure can be obtained after the coat heat treatment where full vaporization of PEG chain structure takes place leaving cavities behind. The early visual inspection of the coat showed a fully adherent structure but there was observed fine ashes on the surface which can be defined as the residuals of extra carbon content resulting from the PEG vaporization. Figure 6 shows the SEM surface morphology of sample P20. Two different textures are observed in the image referred to as areas ' $a$ ' and ' $b$ '. In addition, some agglomerated grains are observed at other areas. Tran et. al in [26] related the presence of agglomerated clusters to the presence of water added to the alcohol as a solvent. According to their theory, the water viscosity is higher than that of the alcohol. Consequently, the coarsening process of the nanoparticles that dissolved in water takes less time than that dissolved in alcohol resulting in agglomerated clusters.

At higher magnification area a as shown in Figure 6 to the right, there exists well defined loosely packed spherical arrays. Same structure was observed in [26] and [27] where they defined this structure as a function of the increase of the PEG content as a surfactant. It has a great role in obtaining a smooth surface with an increased sphericity in the existing particles. On the other hand, area $b$ shows well defined pores or voids in the structure. These pores are a result of the vaporization of the PEG chains through the heat treatment stage. They are responsible for entrapping more solar energy thus increasing the absorptivity as discussed earlier.
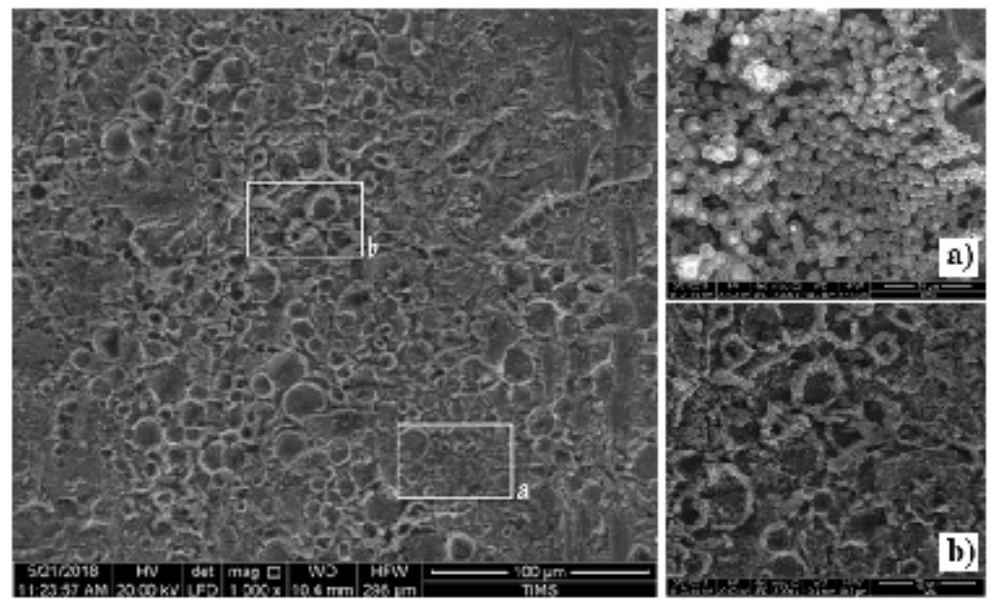

Figure 6- SEM image for sample P20 with magnified areas a and $b$ for investigation

\subsection{Elemental Analysis Through EDX:}

To have a closer look at the existing phases and analyze the presence of all elements seen in the SEM analysis. EDX analysis was held at several structures for validation. Figure 7 shows the EDX analysis for area a that has been discussed earlier in Figure 6. It can be observed that there exists high content of copper and oxygen which validates that the particles shown can be particles of copper oxide. A small amount of $\mathrm{Fe}$ and $\mathrm{Cr}$ resembles the SS in the base substrate. A low carbon content may correspond to the presence of carbon residual compounds as a result of the breakdown of PEG from the structure where voids are left behind. 


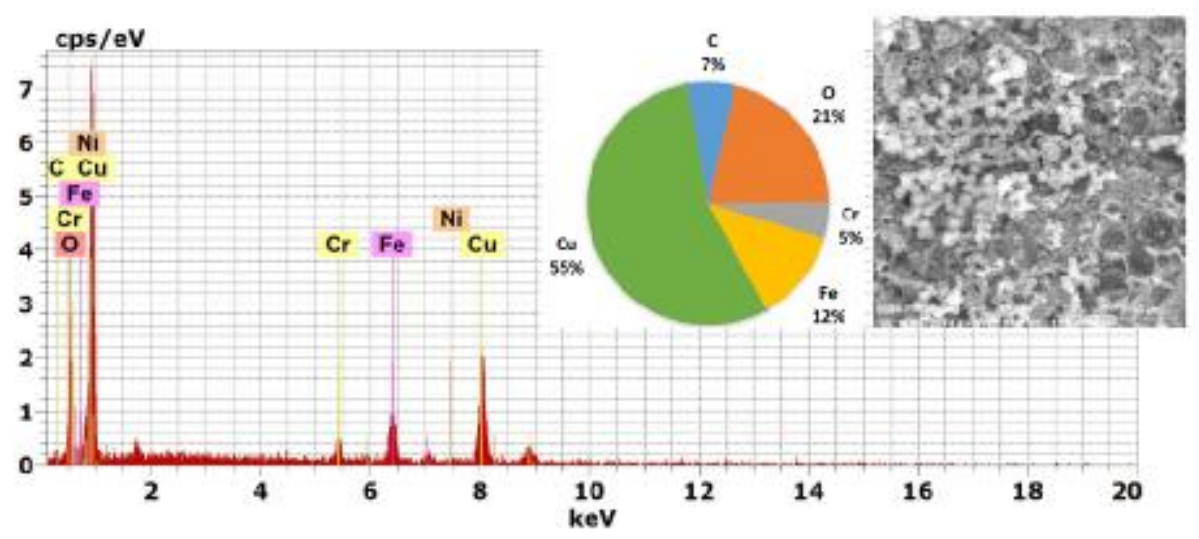

Figure 7 - Area a EDX analysis

Investigating area $b$ where the voids are seen, EDX analysis is shown in Figure 8. A lower content of $\mathrm{Cu}$ and Oxygen can be seen which means that the voids may not contain much copper oxide content. However, the presence of some percentages of $\mathrm{Fe}, \mathrm{Ni}$ and $\mathrm{Cr}$ correspond to the base metal which verifies that there's a very thin layer of coat at the voids areas that can be visually distinguished through the SEM images.

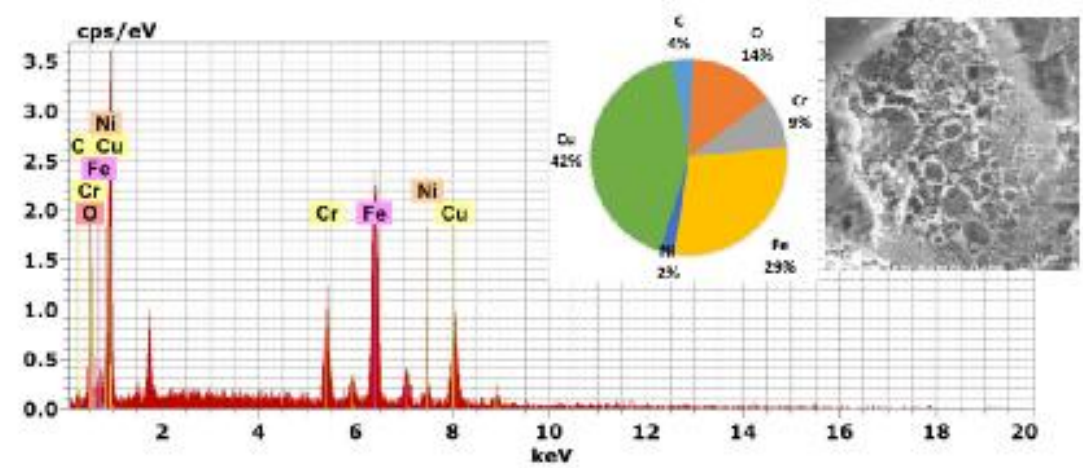

Figure 8 - Area b EDX analysis

\section{CONCLUSION}

Successful sol-gel preparation of copper oxide was experimentally carried on with variable PEG wt\%. Stainless steel samples were dip coated with the prepared solution and heat treated up to $600^{\circ} \mathrm{C}$. Visual inspection has concluded that the coats were fully adherent and smooth on the surface of the substrate with some excess carbon at the surface for an increased amount of PEG. Best absorptivity and emissivity results were for the solution prepared with the highest PEG wt\% that produced a selectivity $\mathrm{S}$ of $\alpha / \varepsilon=$ 96.38/69.4. The high emissivity strongly recommends the usage of a highly reflective layer underneath the copper oxide film in order to suppress those high emissions in the IR range. Measured bandgaps was between $2.5 \mathrm{eV}-3.03 \mathrm{eV}$. SEM analysis validated the existence of spherical particles of copper oxide in addition to pores in higher PEG content which was not seen in the low content samples. EDX analysis validated the presence of copper oxide through the presence of copper and oxygen content in addition to some carbon corresponding to the presence of a bond between the PEG and the copper particles during sol-gel preparation. 


\section{REFERENCES}

[1] S. Jillani, M. Jelani, N. U. Hassan, S. Ahmad, and M. Hafeez, "Synthesis, characterization and biological studies of copper oxide nanostructures," Materials Research Express, vol. 5, no. 4, 2018.

[2] A. Amri, Z. T. Jiang, T. Pryor, C. Y. Yin, and S. Djordjevic, "Developments in the synthesis of flat plate solar selective absorber materials via sol-gel methods: A review," Renewable and Sustainable Energy Reviews, vol. 36, pp. 316-328, 2014.

[3] A. Y. Oral, E. Menşur, M. H. Aslan, and E. Başaran, "The preparation of copper(II) oxide thin films and the study of their microstructures and optical properties," Materials Chemistry and Physics, vol. 83, no. 1, pp. 140-144, 2004.

[4] S. Thiagarajan, A. Sanmugam, and D. Vikraman, "Facile Methodology of Sol-Gel Synthesis for Metal Oxide Nanostructures," in Recent Applications in Sol-Gel Synthesis, 2017.

[5] D. S. C. Halin, I. A. Talib, A. R. Daud, and M. A. A. Hamid, "Characterizations of Cuprous Oxide Thin Films Prepared by Sol-Gel Spin Coating Technique with Different Additives," vol. 2014, pp. 1141-1145, 2014.

[6] H. Hashim, S. S. Shariffudin, M. S. P. Sarah, and N. I. Nasir, "The characterization of copper oxide with different molar concentration using sol-gel spin coating," in IEEE International Conference on Semiconductor Electronics, Proceedings, ICSE, 2016, vol. 2016-Septe, pp. 224227.

[7] P. Mallick and S. Sahu, "Structure, Microstructure and Optical Absorption Analysis of CuO Nanoparticles Synthesized by Sol-Gel Route," Nanoscience and Nanotechnology, vol. 2 , no. 3, pp. 71-74, 2012.

[8] M. Bibi, Q. ul A. Javed, H. Abbas, and S. Baqi, "Outcome of temperature variation on sol-gel prepared $\mathrm{CuO}$ nanostructure properties (optical and dielectric)," Materials Chemistry and Physics, vol. 192, pp. 67-71, 2017.

[9] J. Livage, M. Henry, and C. Sanchez, "Sol-Gel Chemistry of Transition Metal Oxides," Progress in Solid State Chemistry, vol. 18, no. 4, pp. 259-341, 1989.

[10] S. Saadat Niavol and F. E. Ghodsi, S. S. Niavol, and F. E. Ghodsi, "Effect of pH on the Properties of Nanocrystalline $\mathrm{CuO}$ Thin Films Deposited by Sol-Gel Process," ISSN Russian Journal of Physical Chemistry A, vol. 003660244, no. 1, pp. 84-87, 2013.

[11] S. R. Ray, "Preparation of copper oxide thin film by the sol-gel-like dip technique and study of their structural and optical properties," Solar Energy Materials and Solar Cells, vol. 68, no. 3-4, pp. 307-312, 2001.

[12] M. Gupta, V. Sharma, J. Shrivastava, and A. Solanki, "Preparation and characterization of nanostructured $\mathrm{ZnO}$ thin films for photoelectrochemical splitting of water," Bulletin of material science, vol. 32, no. 1, pp. 709-716, 2009.

[13] P. Vařák, B. Śvecová, D. Horkavcová, and S. Vytykáčová, "The preparation and characterization of copper-containing thin films prepared by the sol-gel method on various glasses," Ceramics - Silikaty, vol. 61, no. 2, pp. 99-105, 2017.

[14] V. Patil, D. Jundale, S. Pawar, M. Chougule, P. Godse, S. Patil, B. Raut, and S. Sen, "Nanocrystalline $\mathrm{CuO}$ Thin Films for H2S Monitoring: Microstructural and Optoelectronic Characterization," Journal of Sensor Technology, vol. 01, no. 02, pp. 36-46, 2011.

[15] P. Samarasekara and N. G. K. V. M. Premasiri, "Spin Coated Multilayered Cupric Oxide Thin Films and their structural properties," arXiv preprint, vol. 4, no. 2, pp. 8-13, 2015.

[16] Z. N. Kayani, Y. Ali, F. Kiran, I. Batool, M. Z. Butt, S. Riaz, S. Naseem, M. Umer, S. Riaz, and S. Naseem, Fabrication of Copper Oxide Nanoparticles by Sol-gel Route, vol. 2, no. 10. Elsevier Ltd., 2015.

[17] J. Jayaprakash, N. Srinivasan, and P. Chandrasekaran, "Surface modifications of $\mathrm{CuO}$ nanoparticles using Ethylene diamine tetra acetic acid as a capping agent by sol-gel routine," Spectrochimica Acta - Part A: Molecular and Biomolecular Spectroscopy, vol. 123, pp. 363-368, 2014.

[18] J. Jang, S. Chung, H. Kang, and V. Subramanian, "P-type $\mathrm{CuO}$ and $\mathrm{Cu} 2 \mathrm{O}$ transistors 
derived from a sol-gel copper (II) acetate monohydrate precursor," Thin Solid Films, vol. 600, pp. 157-161, 2016.

[19] V. Usha, S. Kalyanaraman, R. Thangavel, and R. Vettumperumal, "Effect of catalysts on the synthesis of $\mathrm{CuO}$ nanoparticles: Structural and optical properties by sol-gel method," Superlattices and Microstructures, vol. 86, pp. 203-210, 2015.

[20] Z. Chen, A. Jain, and T. Boström, "Simulation of Anti-reflection Coated Carbonaceous Spectrally Selective Absorbers," Energy Procedia, vol. 58, no. 1876, pp. 179-184, 2014.

[21] C. J. Chen, Physics of Solar Energy, no. 3. 2009.

[22] N. Zayyoun, B. Jaber, L. Laânab, E. Ntsoenzok, and R. Bekkari, "Effect of solvent on the morphological and optical properties of $\mathrm{CuO}$ nanoparticles prepared by simple sol-gel process," journal of material enviromental science, vol. 7, no. 5, pp. 1791-1797, 2016.

[23] O. Stenzel, Optical Coatings: Material Aspects in Theory and Practice. Springer Heidelberg New York Dordrecht London, 2014.

[24] I. Z. Luna, L. N. Hilary, A. M. S. Chowdhury, M. A. Gafur, N. Khan, and R. A. Khan, "Preparation and Characterization of Copper Oxide Nanoparticles Synthesized via Chemical Precipitation Method," OALib, vol. 02, no. 03, pp. 1-8, 2015.

[25] A. S. Ismail, M. F. Malek, M. A. R. Abdullah, and M. H. Mamat, "Effect of Polyethylene Glycol Concentration on the Formation of Aluminium-doped Zinc Oxide Nanorods ( a ) ( b )," vol. 1109, pp. 471-475, 2015.

[26] T. H. Tran and V. T. Nguyen, "Copper Oxide Nanomaterials Prepared by Solution Methods, Some Properties, and Potential Applications: A Brief Review," International Scholarly Research Notices, vol. 2014, pp. 1-14, 2014.

[27] C. Karunakaran, P. Vinayagamoorthy, and J. Jayabharathi, "Superlattices and Microstructures Electrical, optical and photocatalytic properties of polyethylene glycolassisted sol - gel synthesized Mn-doped TiO 2 / ZnO core - shell nanoparticles," vol. 64, pp. 569-580, 2013. 